\title{
Percepciones sobre la autonomía universitaria de los docentes-investigadores de la Facultad de Farmacia y Bioquímica de la Universidad de Buenos Aires
}

Cecilia Rikap

\section{RESUMEN}

El objetivo de este trabajo es analizar la vigencia del concepto de autonomía universitaria en la Universidad de Buenos Aires (UBA), ante la apertura de vínculos de investigación con empresas de capital. Para ello, se distinguen tres dimensiones de dicha autonomía (corporativa, de la razón y financiera). Se sugiere que es la autonomía financiera la actualmente jerarquizada y que su búsqueda ha orientado a la UBA a la producción para el mercado, direccionando sus investigaciones según demandas privadas que ponen en riesgo a la autonomía de la razón. Asimismo, se sostiene que la crisis de representación de sus órganos de gobierno ha transformado la autonomía corporativa en escudo de necesidades de grupos reducidos. A partir de entrevistas en profundidad a un grupo de docentes-investigadores de una de sus llamadas facultades de investigación, la Facultad de Farmacia y Bioquímica, estudiamos luego cómo son entendidas esas dimensiones de la autonomía universitaria, indagando si tales riesgos aparecen en sus percepciones.

Palabras clave: educación superior, autonomía universitaria, libertad académica, autogobierno, papel del Estado, Argentina. 


\title{
Percepções sobre a autonomia universitária dos docentes-investigadores da Facultad de Farmacia y Bioquímica da Universidad de Buenos Aires
}

\section{RESUMO}

O objetivo deste trabalho é analisar a vigência do conceito de autonomia universitária na Universidad de Buenos Aires (UBA), ante a abertura de vínculos de investigação com empresas de capital. Para isso, se distinguem três dimensões de dita autonomia (corporativa, da razão e financeira). Se sugere que é a autonomia financeira a atualmente hierarquizada e que sua busca tem orientado a UBA à produção para o mercado, direcionando suas investigações segundo demandas privadas que põem em risco a autonomia da razão. Mesmo assim, se sustenta que a crise de representação de seus órgãos de governo tem transformado a autonomia corporativa em escudo de necessidades de grupos reduzidos. A partir de entrevistas em profundidade a um grupo de docentes-investigadores de uma de suas chamadas faculdades de investigação, a Facultad de Farmacia y Bioquímica, estudamos logo como são entendidas essas dimensões da autonomia universitária, indagando se tais riscos aparecem em suas percepções.

Palavras chave: educação superior, autonomia universitária, liberdade acadêmica, autogoverno, papel do Estado, Argentina.

\section{How the teachers-researchers of the Pharmacy and Biochemistry at the Univer- sity of Buenos Aires perceive the university autonomy}

\begin{abstract}
The purpose of this study is to analyze the validity of the university autonomy concept at the University of Buenos Aires (UBA) facing the opening of new links between research and capital companies. To do so, three dimensions of this autonomy can be observed (corporative autonomy, autonomy of reason and financial autonomy). The authors suggest that the financial autonomy is currently the most valuable one and that the attempts to reach it has oriented the UBA to produce for the market, routing the research to meet private demands that put at risk the autonomy of reason. The authors also maintain that the crisis of representation experienced by its government bodies has transformed the corporative autonomy into a necessity shield for reduced groups. Based on in-depth interviews carried out to teachers-researchers in one of its research faculties, the Faculty of Pharmacy and Biochemistry, the authors study the way in which those dimensions of the university autonomy are perceived and try to find out whether those risks show up in their perceptions or not.
\end{abstract}

Key words: higher education, university autonomy, academic liberty, self-governance, role of the State, Argentina.

Recepción: 08/01/16. Aprobación: 19/04/16. 


\section{Presentación y planteo del problema}

En sólo dos años se celebrarán 100 de la Reforma Universitaria de 1918 en Córdoba, Argentina. Es esta ocasión suficiente para retomar, una vez más, la discusión en torno al concepto de autonomía universitaria (AU), corazón de esta institución desde su origen medieval. Sugerimos que, a lo largo de la historia de la universidad, ha variado la dimensión jerarquizada del concepto de AU.

La Universidad nace en el siglo XIII ${ }^{1}$ como una corporación o gremio de estudiantes o maestros. Al igual que los demás gremios medievales, se caracterizó por el reclamo de independencia de la justicia civil, del rey, príncipe o señor feudal dueño de las tierras donde ella se asentaba. Se edificó así a partir de la demanda de autonomía que, en aquel contexto, remitía a las mayores libertades de maestros y estudiantes con respecto al resto de sus comunidades, y a su consiguiente búsqueda de autogobierno. Es decir que la dimensión jerarquizada por este modelo fue la autonomía corporativa (Rüegg, 2003).

El modelo de Universidad Ilustrada que, aunque en disputa con la Universidad Imperial, es la concepción dominante entre el siglo XIX y mediados del XX, jerarquizó la autonomía de la razón en un sentido kantiano; noción que hoy suele reinterpretarse como libertad académica (Rikap, 2014). Finalmente, desde mediados del siglo pasado, y en línea con un contexto que interpretamos como de creciente diferenciación intrínseca del capital (Levín, 1997), la universidad inicia una nueva etapa, aún en proceso de consolidación, en el marco de la cual se pondera crecientemente la autonomía financiera (Rikap, 2015a). En este escenario afloran preguntas en torno a la vigencia de las dimensiones de autonomía corporativa y de la razón, así como también sobre las posibilidades efectivas de conquista de autonomía financiera en el caso de la universidad pública.

En este escenario general, nos proponemos analizar la vigencia del concepto de AU en la Universidad de Buenos Aires (UBA), ante su vinculación con empresas de capital en los últimos 25 años. Propondremos, a partir de conjugar el análisis de los cambios recientes con las percepciones de sus propios protagonistas, que la autonomía financiera aparece como prerrequisito y a la vez como obstáculo de la autonomía corporativa y de la razón en la UBA, en particular en su Facultad de Farmacia y Bioquímica (FFyB). Ante la insuficiencia presupuestaria, se justifica el ingreso al mercado para conseguir recursos y, al mismo tiempo, garantizar la diversificación de sus fuentes de financiamiento. Sin recursos suficientes las otras dos dimensiones de la AU correrían serios riesgos. Sin embargo, y al mismo tiempo, sugeriremos que al aceptar financiamiento privado los investigadores ven afectada su autonomía de la razón o libertad académica, dado que sus investigaciones resultan orientadas por intereses externos, particulares.

Por otra parte, este proceso ha llevado a la UBA a asumir características empresariales, incluso en sus órganos de toma de decisiones donde, aunque formalmente se mantengan estructuras de cogobierno, un pequeño grupo toma las decisiones, en semejanza al board de una empresa. Estas características se distancian de la democracia universitaria promulgada, entre otras, por la referida Reforma del '18. De manera que la autonomía corporativa también correría riesgos en este escenario. Nos preguntamos entonces si estos peligros potenciales recién mencionados se corresponden o no con las percepciones de aquellos docentes-investigadores de la FFyB de la UBA que se destacan, entre otros motivos, por estar a cargo de grupos que realizan o han realizado investigaciones financiadas por el sector privado.

\footnotetext{
${ }^{1}$ La Universidad de Bolonia, en el marco de una contienda contra la Universidad de París, inventó haber nacido en el siglo XI. Sin embargo, estudios recientes ubican el nacimiento de la Universidad en el Siglo XIII (Rüegg, 2003).
} 
A los fines de contextualizar nuestra investigación, en la próxima sección trabajamos a partir de distintos autores en el concepto de AU desde las dimensiones propuestas (corporativa, de la razón y financiera), y en las dos secciones subsiguientes exploramos dichas tres dimensiones de la AU en la UBA durante los últimos 25 años. Luego, resumimos la metodología utilizada para la selección de la muestra de docentes-investigadores entrevistados, incluidos los motivos por los cuales fue elegida, dentro de la UBA, la FFyB como caso de estudio. Por último, exponemos los resultados de las entrevistas realizadas, y presentamos algunas reflexiones finales.

\section{Las tres dimensiones de la AU: breves reflexiones para contextualizar nuestro estudio}

Desde fines del siglo pasado, diversos autores identifican una preocupación creciente por la insuficiencia del financiamiento universitario, en un contexto donde disminuye el apoyo público directo y los costos van en aumento (Slaughter y Leslie, 1999; Michael, 2005; Johnstone, 2012). En este contexto, entendemos a la autonomía financiera como la capacidad de una institución de funcionar sin restricciones presupuestarias. En el caso de la universidad, nos referimos a la capacidad de realizar sus actividades de enseñanza e investigación (Rikap, 2015a). En busca de dicha autonomía financiera diversos autores observan que, a nivel mundial, se asiste a la diversificación de las fuentes de financiamiento de las universidades (Michael, 2005; Vincent-Lancrin, 2006; Castro-Martínez y Sutz, 2011).

Ahora bien, hace casi 50 años, Varsavsky (1969) insistía en que la presión económica y política que recibían las universidades eran medios indirectos de condicionamiento sumamente efectivos. Desde una posición crítica, Slaughter y Leslie (1999) han explicado que los investigadores compiten por financiamiento privado atado a investigaciones orientadas y aplicadas respondiendo ya sea a intereses del Estado o de las más poderosas empresas de capital. Coincidiendo con estos autores, Castro-Martínez y Sutz (2011) observaron que este proceso de diversificación de fondos altera prioridades de investigación y modifica la agenda universitaria. Coincidimos con estos autores en que la búsqueda de mayor autonomía financiera puede erosionar las otras dimensiones de la AU.

A la hora de definir a la autonomía corporativa retomamos a Piironen (2013), para quien la AU implica conservar grados de independencia en relación con toda influencia externa a la universidad. Esas influencias pueden provenir no sólo de quienes financian privadamente a la institución sino también del Estado. En su dimensión corporativa, la AU refiere entonces, al mismo tiempo, a la capacidad de autogobierno interno de la institución y a su independencia con respecto al Estado. Retomamos así la dimensión de la autonomía jerarquizada en los inicios de esta institución como gremio o corporación medieval. Siguiendo a Gieysztor ([1992]2003), la autonomía era entendida como la capacidad de sancionar sus propias leyes y asegurar su cumplimiento. Pero también incluía el reconocimiento legal de que la Universidad era una corporación en relación con el mundo exterior.

En la actualidad, en relación con la dimensión interna de la autonomía corporativa, Cummings et al. (2011) encuentran una nueva retórica que apunta a modificar la estructura de gobernanza de los asuntos académicos. Se instalan órganos presididos por autoridades de gestión de la universidad, que podrán o no estar secundados por miembros del cuerpo docente. Asimismo, las distintas funciones de gobierno son crecientemente vistas como puestos gerenciales análogos a los de las empresas de capital. En este sentido, retomamos a Pïronen (2013) cuando considera que en la Universidad presente se yuxtaponen el ideal colegiado de toma de decisiones, con mecanismos importados del management empresarial. Este último, sostiene, no asegura la libertad académica, que nosotros reinterpretamos integrada a la autonomía de la razón. 
Completando la referencia a la autonomía corporativa, en cuanto a la relación de la universidad con el Estado, encontramos que éste ha colocado en segundo plano su función de proveedor de recursos no condicionados (o de modalidad block-grant). Hazelkorn (2005) indicó que dentro de las universidades el presupuesto asignado de manera directa por su correspondiente gobierno también está tendiendo a repartirse en función de criterios competitivos, y basado en evaluaciones sobre las investigaciones realizadas. Este proceso, entendemos, es el que se intenta conceptualizar a partir de la transición a "Estado evaluador", planteado inicialmente por Neave (1988), mediante el cual se ha puesto en cuestión la noción tradicional de autonomía corporativa como institución independiente del Estado.

A su vez debemos alertar, como mencionamos más arriba, que las transformaciones mencionadas también afectan a la autonomía de la razón. Esta última había sido la dimensión jerarquizada por la Universidad Ilustrada. Para la Ilustración Moderna el pensamiento, actividad exclusivamente humana, debía ejercerse de manera autónoma (Kant, [1784]2009).

Kant (1784]2009), en su intento por divorciar a la ciencia de la teología, acusa de minoría de edad del pensamiento a aquél que sigue atado a explicaciones religiosas. Identifica a la Ilustración como la época en que el hombre europeo llega a su mayoría de edad. Propone como consigna de este siglo de las luces " ¡Sapereaude! ¡Ten valor para servirte de tu propio entendimiento!" (Kant, [1784]2009: 83). Atreverse a conocer sólo requiere, siguiendo al autor, libertad para ejercitar plenamente la propia razón. Trasladado este principio a la universidad, la autonomía de la razón representó la idea de libertad absoluta tanto para aprender como para enseñar (Anderson, 2004; Bermejo Castrillo, 2008; Morgan, 2011). De aquí que podamos derivar que ser libre para actuar es, para el universitario, ser libre para producir conocimiento.
Ahora bien, Kleinman y Vallas (2001) remarcan que en el proceso de vinculación con empresas se degrada la $\mathrm{AU}$ al responder a los intereses de quien financia, entendida como la capacidad para definir el contenido y los criterios de evaluación de la actividad universitaria para el primero y como autonomía de la ciencia para los segundos. Se corre el riesgo de dejar de lado, o cuando menos posponer, preguntas fundamentales o generales que no captan el interés privado, pero que sí resultan científicamente relevantes. Es decir, se pone en riesgo la autonomía de la razón. Kleinman y Vallas (2001) agregan que el conocimiento público financiado privadamente puede contener cláusulas de confidencialidad.

Siguiendo a Slaughter y Leslie (1999), la autonomía de la razón también peligra frente a los procesos de evaluación externa del desempeño de los docentes-investigadores por parte del Estado. Asimismo, en la actualidad, el ascenso y permanencia en la academia está asociado a criterios meritocráticos "cuantificables", en particular, a la cuantificación de los resultados de la actividad científica (Harari-Kermadec, 2016; Vincent-Lancrin, 2006). Para Harari-Kermadec (2016), esos mecanismos de cuantificación y estandarización apuntan a reducir la actividad de investigación a un trabajo rutinario, productor de mercancías, proceso que entendemos repercute negativamente sobre la autonomía de la razón.

Llegado a este punto nos preguntamos, ¿cuál es el lugar que tiene hoy la $\mathrm{AU}$ en sus tres dimensiones? Es posible pensar que la vinculación de la universidad con terceros resulta en una negociación desigual donde los beneficios de los resultados potenciales obtenidos son apropiados por las empresas de capital más poderosas, llamadas por Levín (1997) de capital potenciado, que dominan los circuitos de innovación en los cuales participan.

De manera que, en el ejercicio de buscar libremente la venta de sus productos como parte de una práctica de diversificación de sus fuentes de 
financiamiento, en un contexto de búsqueda de autonomía financiera de la Universidad, podemos considerar que la AU coincide con la idea de libertad del homo-mercator o productor de mercancías descripto por Marx ([1867] 1973). Éste es libre de decidir autónomamente qué producir, sin depender directamente de ningún otro productor. Sólo debe ajustarse a las leyes de oferta y demanda. Así entendida, la autonomía financiera es la versión universitaria de la autonomía mercantil. Cada centro o investigador actúa, sin necesidad de reconocerlo explícitamente, como un productor privado e independiente de mercancías (Marx, [1867]1973); su conciencia se ha convertido en la conciencia del homo-mercator.

En este marco consideramos que el docenteinvestigador no escapa a las pautas generales que se imponen sobre la conciencia del productor de mercancías. El científico, al igual que el resto de la humanidad, se formó y vive bajo determinadas relaciones sociales. Es un sujeto que se reproduce, como todo homo-mercator, por medio de la compra y venta de mercancías. En este escenario, la norma es aceptar que el trabajo científico cambió y que hay que adaptarse al cambio para seguir asegurando la propia reproducción material, ahora a través de nuevas relaciones mercantiles.

En un contexto donde se rompen los límites con la Universidad, el Mercado aparece expandiéndose sobre toda área que, con anterioridad, había logrado organizarse prescindiendo de él. En ese sentido, Berman (2012) remarca que el cambio identificado en la producción de conocimiento en la universidad puede verse como una instancia de un patrón más general, mientras que, desde el último cuarto del siglo XX, la lógica de mercado se expandió a campos en los cuales tradicionalmente había ocupado un rol menor o no ocupaba rol alguno. En este marco general, y a partir de las aproximaciones conceptuales señaladas, nos proponemos a continuación explorar las tres dimensiones de la $\mathrm{AU}$ mencionadas en la UBA durante los últimos 25 años. Y, a los fines de ordenar nuestra investigación, nos preguntamos si en la UBA se han dado estos procesos generales de limitación de la autonomía financiera y corporativa que repercuten restringiendo la autonomía de la razón y si, en caso afirmativo, perviven márgenes para enseñar e investigar retomando a esta última.

\section{La relación mercantil inserta en la relación universitaria: la búsqueda de autonomía financiera y su impacto sobre la autonomía de la razón en la UBA}

Teniendo en cuenta que partimos de escenarios de fuerte deterioro presupuestario en la UBA (Rikap, 2015b), la vinculación con empresas aflora en el último cuarto de siglo en esta universidad como mecanismo para conquistar autonomía financiera y superar la dependencia del presupuesto público (PP). A primera vista, resulta coherente el hincapié que asignan algunos autores a que fue la merma de dicho presupuesto la que explica la apertura al financiamiento privado, en línea con las nuevas tendencias mundiales (Di Meglio y López Bidone, 2010; Llomovatte, 2006; Libecap, 2005; García de Fanelli, 1993). Diferenciándose de estos autores, Krotsch (1990) postuló que al copiar políticas de los países centrales se orientó la producción científica al mercado, buscando reemplazar la dependencia económica estatal.

Sin embargo, la realidad no es tan lineal en la UBA. A modo de ejemplo, a la hora de dar cuenta de las facultades con mayores necesidades presupuestarias, basta mirar el estado de los edificios donde funcionan las facultades de Psicología, Ciencias Sociales (incluso su edificio nuevo se ubica en una zona poco segura y ya ha sufrido incidentes) y Filosofia y Letras. Son éstas, justamente, tres de las facultades con menores recursos propios (RP) (Rikap, 2015a y 2015b).

A su vez, en contraposición a los noventa, a partir del 2000 se ha otorgado un PP creciente a la UBA (al igual que a las demás universidades nacionales), si bien desde 2006 dicho aumento debe matizarse por 
el proceso inflacionario (Rikap, 2015a y 2015b). ${ }^{2}$ De hecho, la preocupación por la falta de recursos es reconocida como un problema no resuelto en la UBA (Doberti, 2014).

En el periodo analizado los RP no disminuyen su importante ritmo de crecimiento más allá del aumento sostenido del PP, siendo la UBA la mayor receptora de aquéllos entre las universidades nacionales, concentrando 24\% del total de RP en 2011 (Ministerio de Educación, 2011). Ahora bien, a nivel interno, representaron sólo el 20\% del PP recibido en 2011. De modo que, en términos financieros, la UBA mantiene su dependencia estatal. Sin embargo, del total del PP, el 93\% correspondió a "Educación y Cultura" en aquel año, es decir, al pago de salarios de su personal que no puede pagarse con RP. Sólo el 1\% fue destinado al rubro "Ciencia y Técnica". ${ }^{3}$ Esta cifra representó, aproximadamente, un tercio de los RP de la UBA (Ministerio de Educación, 2011).

$\mathrm{Si}$ bien en la partida de salarios se incluyen las dedicaciones a la investigación, éstas son un porcentaje minoritario - alrededor del 16\% del total de dedicaciones según la UBA (2011a) - Podemos pensar entonces que los RP constituyen una fuente indispensable para dicha actividad. Igualmente, debemos agregar que un papel similar desempeñan los ingresos públicos obtenidos por medio de mecanismos competitivos.

Sostenemos que la limitada asignación presupuestaria sin condicionamientos para esta área restringe la autonomía de la razón en la UBA. Las empresas invierten de acuerdo con sus propios análisis de costo-beneficio e influyen así sobre qué se investiga. Este tipo de acciones plantea un potencial riesgo de subordinación de la autonomía de la razón a la autonomía financiera. Por otra parte, la obtención de fondos por mecanismos competitivos también orienta las investigaciones dado que, en general, se priorizan proyectos de ciencia aplicada y que puedan asegurar resultados en el plazo que dura el subsidio. Volveremos sobre este punto más adelante.

Coincidimos con Riquelme y Langer (2013), quienes explican que en la UBA el avance de las actividades de extensión y transferencia, y su progresiva indistinción o trasmutación con la tarea de investigación, conducen a una pérdida de $\mathrm{AU}$ en las dimensiones que aquí hemos llamado corporativa y de la razón. Para estos autores, la Universidad pierde autonomía en la toma de decisiones y ello impacta sobre la libertad académica, la cual se ve seriamente afectada por intereses que le son ajenos. Alertan también sobre la ausencia de claridad respecto de las consecuencias de este proceso entre los docentes-investigadores.

Por último, a este respecto, distintos autores en Argentina comparten la crítica de que la realización de transferencias, consultorías o asistencias técnicas reduce el tiempo disponible para investigación libre o definida colectivamente en la Universidad, institutos de investigación, etcétera y que se ha avanzado en un proceso mercantilizador de la educación superior (Gentili y Levy, 2005; Toscano, 2005; Llomovatte, 2006; Rikap, 2012).

\section{Autonomía corporativa en la UBA: crisis de representatividad e influencia del Estado evaluador y promotor}

Bajo la dimensión corporativa recordemos que remitimos tanto a la capacidad de autogobierno, es decir, a la autonomía interna de la UBA, como al tipo de relación que entabla con el Estado.

\section{La relación política inserta en la relación universitaria}

Repasemos primeramente la estructura de los órganos de gobierno de la UBA. Cuenta con un Consejo

\footnotetext{
${ }^{2}$ A modo de ejemplo, el aumento real del PP, considerando el Índice de Precios al Consumidor, fue del 1.17\% en 2010 y del 5.7\% en 2011.

${ }^{3}$ La diferencia corresponde a los hospitales dependientes de la UBA.
} 
Superior (CS) integrado por los 13 decanos (todos ellos profesores regulares), cinco profesores regulares, cinco estudiantes y cinco graduados. ${ }^{4} \mathrm{~A}$ ellos se suma el rector. Es decir que los profesores regulares gozan de mayoría absoluta en el máximo órgano de cogobierno de la UBA.

Cada facultad está gobernada por un Consejo Directivo (CD) (el Ciclo Básico Común carece de órganos de cogobierno y sólo cuenta con un director elegido por el rector) y un decano electo por su CD. ${ }^{5}$ Cada CD se compone de 16 miembros: cuatro estudiantes, cuatro graduados y ocho profesores regulares. En caso de empate, define el decano de esa facultad. Es decir, nuevamente los profesores tienen mayoría absoluta (el decano debe ser profesor regular). Los empleados no docentes no son miembros del cogobierno aunque tienen un representante con voz, pero sin voto. Todos los consejeros (superiores y directivos) conforman la Asamblea Universitaria, facultada para elegir rector y reformar el Estatuto (UBA, 1960).

El claustro profesoral, que está facultado para elegir a sus representantes profesores en ambos órganos (CS y CD), excluye a todos los auxiliares $(76.9 \%$ en 2011), quienes sólo en caso de ser graduados de la UBA pueden participar políticamente pero en el claustro de graduados, y a los profesores interinos (más del 50\% del total) (UBA, 2011a). Así, la enorme mayoría de los docentes carece de derechos políticos; no es ciudadano universitario. En algunas facultades la desproporción se acrecienta por las cifras más acuciantes de interinatos. Entre otros debates pendientes encontramos la inclusión de los no docentes y la posibilidad de disminuir la desproporción entre profesores y estudiantes.

Actualmente, ha crecido la concepción de que en universidades como la UBA la estructura actual del cogobierno "ha permitido que se perpetúe en el poder una elite que actúa en forma corporativa y que defiende con dureza sus privilegios" (Buchbinder, 2005: 233). Buchbinder (2004) advierte que abunda el clientelismo a la hora de decidir sobre las designaciones interinas y se controlan los concursos. Y lo mismo podemos pensar que sucede con la asignación de financiamiento para proyectos de investigación, los llamados UBACyT. De manera que las limitaciones a la autonomía corporativa en la UBA podemos pensar que repercuten sobre la autonomía de la razón, tanto para enseñar como para investigar, de quienes no sean afines a las autoridades. Según Kandel (2005), en la UBA es escasa la discusión sobre su autogobierno; predomina la idea de libertad negativa tradicional: la no intervención del Estado.

A su vez, Fernández Lamarra et al. (2011) sostienen que en las universidades nacionales, en general, predomina una estructura de división del trabajo vertical dentro de la carrera docente. La mayoría de los 826 docentes encuestados por estos autores coincidió en que tienen una escasa influencia en la toma de decisiones en su facultad (85.9\%) y en su universidad (92\%).

En este contexto, se ha abierto una discusión en torno a los alcances de la AU en la UBA. Para Finocchiaro (2004) esta universidad ha traspasado los límites de su autonomía. Otros autores, en cambio, reconocen la falta de representatividad de los órganos universitarios de gobierno y la necesidad de reformas democráticas, pero igualmente coinciden en la necesidad de mantener la AU (Buchbinder, 2005 y 2006; Buchbinder y Marquina, 2008; Beigel, 2010).

\section{Las relaciones de poder entre la Universidad y el Estado}

Lentamente, desde fines de los ochenta, el Estado comenzó a acompañar su función de proveedor de

\footnotetext{
${ }^{4}$ Cabe señalar que dentro del claustro de graduados se requiere que al menos un representante sea docente auxiliar. Si bien ello incluye, aunque sea marginalmente, a los docentes auxiliares, esta opción queda circunscrita sólo a aquéllos graduados en la UBA.

${ }^{5}$ Dejamos afuera de nuestro análisis a los colegios preuniversitarios y a las juntas por carrera o departamento, dada la extensión de este trabajo. Igualmente, las conclusiones no se modifican sustancialmente si los incorporáramos.
} 
recursos con roles de evaluación y promoción de políticas universitarias orientadas a satisfacer necesidades del (resto del) sector productivo. Con anterioridad, la vinculación de la universidad con el resto del sector productivo no ocupaba un lugar significativo en las políticas científicas.

Se ubica en los noventa el fin del modelo de Estado Benevolente en Argentina, cuya casi exclusiva relación con las universidades públicas es el otorgamiento de subsidios en bloque (Brunner, 2012), y el paso a un Estado Evaluador de las actividades de enseñanza e investigación (Neave, 1988 y 2012) y promotor del vínculo con el sector privado (Rikap, 2015a).

Un hito en este proceso fue la sanción de la Ley de Educación Superior (LES), la cual no aseguraba la gratuidad de la educación superior pública y autorizaba a las universidad nacionales a cobrar aranceles. El aseguramiento de la gratuidad de la educación superior fue restituido en 2015 para las carreras de grado de las universidades nacionales aunque, salvo alguna excepción, las universidades mantuvieron la gratuidad del grado durante esos 20 años.

Ahora bien, el principal cambio que introdujo la LES, de acuerdo con el rol del Estado como evaluador, fue la creación de la Comisión Nacional de Acreditación y Evaluación Universitaria (CONEAU). Esta institución evalúa y acredita todas las carreras de posgrado y aquellas de grado reguladas por el Estado (http://www.coneau.gov.ar/CONEAU/index.php/component/content/article/99-ique-es-laconeau; Consulta: 19 de marzo, 2015). Tanto la LES como la posterior Ley de Transferencia Tecnológica fomentaron la transferencia de conocimientos universitarios, principalmente a las empresas (Riquelme y Langer, 2013).

La UBA rechazó inicialmente la LES como una obstrucción a su AU presentando un amparo judicial donde denunciaba los artículos que, según sus autoridades, contradecían aquel principio. Esta presentación judicial dio lugar al conocido "Fallo Marinelli" (apellido del juez responsable) en el que se reconoce el carácter inconstitucional de la LES en algunos de esos artículos. Pero lo interesante es que aun habiendo ganado el fallo, las autoridades de la UBA terminaron acordando con la CONEAU los criterios de evaluación y acreditación de sus carreras (Finocchiaro, 2004). En línea con Doberti (2014), coincidimos en que la adaptación a los cambios propuestos por la CONEAU a la UBA ha dependido del grado de resistencia de sus claustros.

A partir del 2000, el alcance de la CONEAU se profundizó. Otra continuidad con los noventa es la autorización para generar RP, la cual va en el sentido de asegurar mayores grados de autonomía financiera. Las universidades dictan sus normas sobre "venta de bienes, productos, derechos o servicios, subsidios, contribuciones, herencias, derechos o tasas por los servicios que presten, así como todo otro recurso que pudiera corresponderles por cualquier título o actividad" (http://www.diputados.gov.ar/proyectos/ proyecto.jsp?id=149818). De manera que no sólo cambió la orientación del Estado para con la universidad, sino que el primero apuntó a que la segunda busque fuentes complementarias de financiamiento (Rikap, 2 015b y 2012). Es decir que el Estado fomenta la orientación externa de las investigaciones de la UBA y las afecta de manera directa por medio de su acción como evaluador. Podemos pensar que ambas acciones repercuten sobre la autonomía de la razón.

De manera que las dos aristas de la autonomía corporativa se han puesto en discusión en el último cuarto de siglo. Dada la crisis de representación, la mayoría de los docentes y todos los no docentes no participan en la elección de sus representantes. A su vez, los profesores regulares cuentan con mayoría absoluta en todas las instancias de decisión. Tampoco existen instancias de participación política de toda la comunidad universitaria, reconocidas estatutariamente, por fuera del llamado a elecciones. Los reclamos al Estado, así como las decisiones sobre diversificación de fuentes de financiamiento, quedan en manos del claustro de profesores. Entonces, 
¿hasta qué punto lo que se pone en juego cuando las autoridades de la UBA declaran una amenaza sobre la AU es dicha autonomía? ¿Es posible hablar de autonomía corporativa en una institución cuyos órganos de gobierno revisten las características antes enunciadas? Y en relación con la autonomía de la razón nos preguntamos, ¿la apertura a procesos de evaluación de las actividades en enseñanza e investigación no es acaso otra fuente de orientación externa de estas actividades, que por lo tanto influye sobre la autonomía de la razón?

En las últimas dos secciones estudiamos las tres dimensiones definidas de la AU en la UBA en los últimos 25 años. ¿En qué medida los peligros que hemos encontrado son percibidos por sus protagonistas? Para dar cuenta de ello, en la siguiente sección elegimos a una de sus facultades y, en particular, determinamos los criterios para seleccionar una muestra de docentes-investigadores a quienes entrevistamos en torno a estas cuestiones.

\section{Selección de estudio de caso y metodología para las entrevistas}

El tamaño, la variedad de actividades y la relevancia intelectual de la UBA la han convertido en una institución única dentro de las universidades nacionales (García de Fanelli, 1993). Es la universidad más grande de Argentina, tanto en cantidad de estudiantes (262 932) como docentes (28 232) (UBA, 2011a y 2011b). La UBA, en parte por su tradición, ocupa de facto el lugar de universidad insignia del país y, según los indicadores nacionales de investigación, es y ha sido la principal universidad en lo que a investigación se refiere (García de Fanelli, 2007). Dejando de lado las críticas a este tipo de rankings, en 2015, en la clasificación internacional de Shanghái, la UBA ocupó el segundo lugar entre las universidades latinoamericanas. Sólo la UBA y la Universidad de San Pablo se encuentran dentro de los primeros 200 puestos.

Dentro de la UBA, la FFyB ha sido reconocida como una de las unidades académicas con mayor importancia asignada a la investigación (García de Fanelli, 2007). Se trata de una facultad pequeña en relación con el tamaño total de la UBA: 4549 estudiantes de grado en 2011, aunque su matrícula de posgrado se incrementó un 21.3\% entre 2004 y 2011 (UBA, 2011b).

La FFyB cuenta con tres carreras de grado: licenciatura en Farmacia, licenciatura en Bioquímica, y la recientemente creada licenciatura en Ciencia y Tecnología de los Alimentos. La oferta de carreras de grado se ve enriquecida por una serie de tecnicaturas. Completan la oferta de formación profesional una amplia gama de posgrados. La maestría internacional en Ciencias Biomédicas constituye un caso particular. La misma fue creada a fines de 2008 en conjunto con la Universidad de Friburgo, de Alemania. Dado que es una maestría internacional, se dicta en inglés.

En 2011 había 894 docentes rentados en la FFyB (UBA, 2011a). En agosto de 2015 realizamos una consulta al Departamento de Personal de esta facultad donde nos informaron que a esa fecha se registraban 1006 cargos docentes rentados y 328 ad-honorem. Esta facultad también presenta limitaciones generales en términos de estabilidad laboral docente. Del total de docentes rentados, casi el 47\% es regular en la FFyB (UBA, 2011a). Este guarismo es sensiblemente mayor que el promedio de la UBA (37\% de docentes regulares rentados). Por supuesto, si contabilizáramos a los docentes ad-honorem la cifra sería sensiblemente menor, dado que no existen los cargos regulares ad-honorem en esta dependencia.

En lo que respecta al área de investigación, la FFyB cuenta con ocho institutos. Sólo uno pertenece exclusivamente a la UBA (el Instituto de Fisiopatología y Bioquímica Clínica). Los siete restantes tienen doble dependencia UBA-CONICET. La importancia de estos institutos se evidencia al observar que, a diferencia del promedio general de la UBA $(21 \%$ sobre docentes rentados y $15.8 \%$ sobre el total de los docentes), se destaca un significativo porcentaje de 
docentes con dedicaciones a la investigación (43\% de los docentes rentados). Por otra parte, debemos agregar a aquella porción de los investigadores de la FFyB que son becarios, los cuales, sin contabilizar las becas otorgadas por el CONICET o la ANPCyT, eran 109 en 2011 (FFyB, 2013).

En los documentos oficiales de la FFyB, tanto en su Plan Estratégico 2014-2018 (FFyB, 2014) como en sus Memorias (FFyB, 2009, 2011, 2013 y 2015), se observa marcadamente el incentivo institucional a la vinculación con el resto del sector productivo. Esta política data formalmente de 1991 con la temprana creación de la Subsecretaría de Transferencia Tecnológica, la cual funciona como oficina de vinculación o enlace de los investigadores con las demandas externas. En una consulta realizada a la página web de la FFyB en 2011 se presentaba más información que la disponible en la actualidad en dicha página. Allí se señalaba que, desde su creación, la Subsecretaría había gestionado 462 convenios de Investigación y Desarrollo y de Asistencia Técnica, se habían ejecutado 13669 Asesorías Técnicas y 2232 Asesorías de Alta Complejidad.

Adicionalmente, se apunta a aplicar en el ámbito de esta facultad el proyecto UBA EMPRENDE, de incubación de empresas productoras de conocimiento científico y tecnológico. Hasta el momento, sin embargo, la FFyB no tiene tradición de creación de start-ups. También se prevé la instalación de una planta farmacéutica, la cual se menciona ya está en proceso de licitación y se inscribe dentro de la política nacional de producción pública de medicamentos (FFyB, 2015).

El análisis detallado de los convenios realizados con terceros entre 1997 y $2011,{ }^{6}$ a partir de los datos provistos por la mencionada Subsecretaría de Transferencia Tecnológica, refuerzan la idea de que estamos frente a un caso estimulante para analizar el impacto de los vínculos con el sector privado sobre la AU. Si a ello agregamos que, tradicionalmente, las áreas de farmacia y bioquímica han sido pioneras a nivel mundial en desarrollar una fluida relación entre las instituciones de educación superior y el correspondiente subsistema de producción (Berman, 2012; Furman y MacGarvie, 2009), consideramos que contamos con motivos suficientes para estudiar las percepciones sobre la AU de investigadores que coordinan o han coordinado este tipo de vínculos.

Realizamos entonces entrevistas en profundidad semi-estructuradas a investigadores de la FFyB seleccionados a partir de identificar a los responsables de los convenios de potencial desarrollo tecnológico de esta institución con terceros. La guía de pautas utilizada (véase el Anexo 1) comprende más cuestiones de las analizadas en este trabajo, dado que formó parte de una investigación más amplia. La misma es resultado de modificaciones y aportes que incorporamos durante la realización del trabajo de campo.

Por otra parte, de acuerdo con Blanchet y Bézille (1985), la no estructuración de la entrevista permite a los entrevistados no percibir las intervenciones como experimentalmente preconcebidas por el entrevistador sino como un intercambio distendido y espontáneo. Al plantear las entrevistas como una conversación, establecimos un diálogo fluido y respetuoso de los tiempos del entrevistado/a. Favoreció esa proximidad mi condición de investigadora y docente en la UBA, dado que ello los hizo sentir en un clima de mayor empatía frente a los problemas planteados.

Se entrevistaron ocho investigadores, incluida una ex decana y ex vicedecana (que en total ocupó funciones ejecutivas durante 16 años, todos ellos durante nuestro periodo de estudio). Su duración promedio fue de una hora y quince minutos. Dentro del grupo de investigadores que han dirigido proyectos

\footnotetext{
${ }^{6}$ En este trabajo se omite el análisis pormenorizado de esta información dado que aquí nuestro foco está puesto en la percepción de los investigadores sobre el proceso y no en los datos fácticos que dan cuentan del mismo.
} 
de potencial desarrollo tecnológico, se procuró inicialmente contactarlos a todos, aunque la cantidad definitiva de entrevistas estuvo determinada por los criterios de saturación teórica (Saltalamacchia, 1997), quedando fuera del análisis uno de los proyectos. El mismo fue descartado, además, porque la contraparte es una fundación dependiente de otra universidad y no una empresa. Por último, con objeto de asegurar el anonimato de los/las entrevistados/as, se procedió a asignar un número a cada entrevista. A continuación, analizamos los resultados obtenidos discriminando por dimensión de la AU.

\section{Percepción sobre la Autonomía Universitaria}

\section{La autonomía financiera en la FFyB}

Encontramos distintos elementos que dan cuenta de la ausencia de autonomía financiera, asociada a la insuficiencia de recursos, en la FFyB. A la pregunta sobre dónde asignarían más presupuesto si pudieran decidir sobre ello, todos los entrevistados refirieron a la existencia de docentes ad-honorem y subrogantes (que realizan tareas correspondientes a cargos superiores a los que revisten) entre los principales problemas que afectan al trabajo docente.

Es difícil la pregunta porque hay tantas cosas. Por un lado, el factor humano hay que cuidarlo mucho [...] Yo creo que el personal no es justo que pase 3, 4 o 5 años una persona sin cobrar, que generalmente son los que más se preocupan y se ocupan. Uno dice se forman, pero igualmente no es justo porque uno come, necesita viajar, vestirse y encima les exigen cursos y capacitación. Y, por otro lado, si pienso en el factor humano tengo que pensar en el lugar de trabajo. Tengo que tener un ambiente lindo, seguro, limpio, ordenado, pintado, iluminado (Entrevista 5).
La existencia de accidentes por deterioro de infraestructura en la FFyB es otro elemento que ilustra las restricciones financieras. Un resultado común de todas las entrevistas realizadas es la necesidad de más espacio para realizar las investigaciones y el reconocimiento de que no se cuenta actualmente con condiciones de trabajo seguras. Todos los entrevistados coincidieron en que el edificio necesita ser acondicionado enormemente.

Tres de los entrevistados recordaron la caída de una porción de techo que impactó sobre un estudiante en un aula magna hace tres años. Recién en 2015 (dos años más tarde) comenzó la adecuación de dicha sala. En la entrevista 4 se mencionó, además, la presencia de roedores en el subsuelo. ${ }^{7}$ Otros dos investigadores enfatizaron que un serio problema es el estado de los caños. También pudimos constatar en la entrevista 4 que se cayó un techo en su bioterio porque en la Facultad de Medicina estaban arreglando un baño ubicado sobre el mismo.

Consultamos adicionalmente a representantes de uno de los gremios docentes de la UBA por las condiciones edilicias de la FFyB. Nos indicaron que, en conjunto con el Centro de Estudiantes, habían realizado una inspección con un arquitecto, docente de la Facultad de Arquitectura, Diseño y Urbanismo. Pudieron constatar que la FFyB no está preparada para la cantidad de estudiantes que la transitan, dado que no cuenta con medidas de seguridad para garantizar su evacuación ante emergencias. Ello está asociado, sobre todo, a que parte de los pasillos que deberían permitir la circulación de estudiantes y docentes fueron ocupados por los laboratorios al necesitar más espacio. En mis visitas a algunos laboratorios para efectuar las entrevistas comprobé la expansión de los institutos con cerramientos de durlock que ocupan porciones de los pasillos, reduciendo el espacio libre para el paso. En uno de los

\footnotetext{
${ }^{7}$ Agregó que el encargado de seguridad e higiene de la FFyB les dijo que las mismas estaban en un basural en el subsuelo de la Facultad de Medicina. Cuando éste se quemó, al quedarse sin sustrato, dispararon por toda la manzana que comunica las facultades de Odontología, Medicina y la FFyB.
} 
pisos se perdió la conexión entre las dos alas de la facultad, para pasar de una a otra hay que subir o bajar un piso y luego retomar por otra escalera.

En un contexto de insuficiencia de recursos, la carencia edilicia requiere tales sumas invertidas y debe lidiar con mayores idiosincrasias que los aumentos salariales. La constatación de estos hechos pone de relieve dicha insuficiencia de recursos y refuerza la hipótesis de que la autonomía financiera no está garantizada en la FFyB.

Todos los entrevistados, así como el personal del área de contaduría de la FFyB consultado a este respecto, coincidieron también en que esta facultad subsiste gracias a los RP. El ex-decano Boveris (2009) señaló la equiparación en los fondos públicos y propios para gastos corrientes de la FFyB para el año fiscal 2009. Indicó que la FFyB tuvo ese año alrededor de $\$ 10$ millones facturados en concepto de utilización del conocimiento en forma directa y por transferencia de tecnología, de los cuales la FFyB podría disponer de, aproximadamente, $\$ 1.5$ millones.

Encontramos ciertas objeciones en torno a las prioridades con las cuales se asignan dichos RP, indicando que para sus autoridades la función principal a garantizar es la enseñanza.

Todo lo que se hace acá en esta facultad de mejoras viene todo de fondos de servicios, fondos propios, y hay prioridades que van más que nada a lo que es alumnos. Pedís tres aires acondicionados y tenés que llenar un montón de papeles a ver si lo conseguís. No es que desde decanato recorren y dicen "acá falta esto y esto", sino que tenés que pedir por favor y es un desgaste (Entrevista 2).

Igualmente, todos coincidieron en que los recursos resultan insuficientes incluso para garantizar condiciones de cursada adecuadas.

Hoy me pasó que fui a dar clases con un cañón que no funciona; sabés que estás jugado porque viene la gente que paga para hacer la maestría; cara de póker "ya lo arreglamos". No es muy cómodo, hay que estar haciendo malabares, y eso no es bueno. [...] más difícil es dar clases cuando no tenemos suficientes insumos y tienen que compartir cosas los estudiantes. Necesitamos más estructura para los estudiantes que entran. Más aún con nuestras disciplinas, por ahí tenés un equipo para 5 personas. (Entrevista 2).

A nivel general, los problemas presupuestarios son percibidos por todos los investigadores como sumamente sensibles. Los mismos afectan sus investigaciones, particularmente las de quienes tienen vínculos más débiles con el sector privado. La necesidad de más recursos para satisfacer las múltiples necesidades edilicias, de equipamiento, de salario para todos los docentes, mejores condiciones de trabajo en general, etcétera. fueron comunes a todos los investigadores entrevistados. Como consecuencia, orientan sus investigaciones en función de los recursos disponibles, lo cual compromete su autonomía de la razón.

Muchas veces uno necesitaría tener una infraestructura mejor dotada, es el caso del ámbito físico del cual disponemos en el instituto, no tanto así en instrumental que desde que estos últimos años el Ministerio tomó la política de equipamiento y sabiendo compartir el equipamiento entre los que son propios y los que disponemos a nuestro servicio, las limitaciones en instrumental no son tantas (Entrevista 1).

Sí, tuvimos que orientar las investigaciones, muchas veces porque a nosotros nos cuesta conseguir equipamiento que es un recurso muy caro y muy necesario actualmente. Generar, pedir subsidios para la compra de ese equipamiento que te lleva tiempo, y que muchas veces los equipos son más caros que el subsidio que te dan. Tenés que armar redes con otros para comprar equipos. Limitaciones en equipamiento te condicionan, por ejemplo, a la hora de 
hacer alguna investigación porque no tenés la herramienta con la cual en el mundo se lleva adelante eso. Se buscan alternativas, uno trata de resolverlo, de eso se trata la investigación. Y las capacidades edilicias también te limitan porque no tenés tanto espacio como necesitarías (Entrevista 4).

Se agrega que dada la necesidad de insumos, sobre todo reactivos y maquinaria importada para modernizar los laboratorios, la FFyB se ve especialmente afectada por los avatares económicos de Argentina. Frente a la falta de recursos, los investigadores intentan sortear los obstáculos con creatividad.

En verano se corta la luz y perdemos todo. Los insumos vienen de afuera y salen un montón. Es como tu casa, tenés algo nuevo y lo cuidás. Acá vamos construyendo sobre lo que está. A lo mejor algo no se puede hacer pero se pueden hacer otras cosas es como que a veces pasan cosas geniales como que se suma mucha gente al CONICET que está buenísimo pero si después no hay subsidios o no hay lugar para todos, si uno se piensa en un conjunto, lo mismo con la docencia, si entran 20 mil personas y luego no los acompañamos pasa lo mismo. Pasa que entra mucha gente al CONICET y "después vemos cómo nos arreglamos". [...] El problema de infraestructura es realmente importante. Los laboratorios nuevos del CONICET están buenísimos, pero la UBA está quedada. Acá no pasa nada, esto va creciendo y no pasa nada, fijate dónde tenemos las heladeras, cómo tenemos las cosas, en esta oficina somos dos cuando antes había una sola persona (Entrevista 2).

Retomando la discusión general sobre la insuficiencia de recursos, el 86\% de los investigadores de la FFyB entrevistados por Juarros (2006) declaró que la búsqueda de mayores recursos era su principal razón para realizar transferencias. En nuestras entrevistas, los investigadores también reconocieron la necesidad financiera como motivo para adoptar la vinculación con terceros. Ahora bien, encontramos que la explicación de este fenómeno trasciende la búsqueda de recursos aunque la misma haya contribuido a que el investigador mire con buenos ojos la vinculación. Entre otros motivos, ha aparecido en diversas entrevistas la consideración de que al vincularse con terceros se contribuye al desarrollo de Argentina.

En particular nos interesa esta relación con la comunidad médica y poder retribuirle a la sociedad con un conocimiento que pueda tomar. Que toda la inversión del Estado le sea devuelta al Estado (Entrevista 8).

\section{La autonomía corporativa interna en la FFyB}

Cuando fueron consultados por los temas que afectan a la autonomía corporativa, la mitad de los investigadores mostró cierto desconocimiento sobre los mecanismos de toma de decisiones. En su análisis sobre la crisis de representación de las universidades Kandel (2005), justamente, hizo hincapié en el abismo que se ha ido construyendo entre representantes y representados; abismo que nos permitiría explicar, al menos en cierta medida, tal desconocimiento.

Entre los investigadores entrevistados en la FFyB que sí manifestaron un mayor conocimiento sobre los procesos de toma de decisiones fueron reconocidas las críticas a las cuales hicimos referencia más arriba en este trabajo, en particular, los problemas asociados al claustro de profesores. Tanto la falta de ciudadanía política de los interinos como de los auxiliares en tanto tales o como parte del claustro docente, en general, fueron identificadas como problemas a solucionar.

Cuando uno dice bueno votan los concursados, es una persona que pasó por un montón de instancias, pero el otro quizás no llegó porque no le dieron la posibilidad [...]. Los regulares cada tanto renovás y 
en el caso de los interinos lo que presentan acá igual es un informe docente. A lo mejor si hace bien eso se los puede involucrar y tener los mismos criterios que con los regulares (Entrevista 2).

Cómo se elige a los que dirigen es un problema muy serio, porque de una llamada autonomía puede pasar a ser un órgano de una gestión determinada y cambia todo el sentido. [...] El problema del claustro docente donde participen los profesores y docentes auxiliares es un problema que está siempre presente y nunca se soluciona. (Entrevista 3).

El tema de los cargos es difícil. Hay muchos interinatos y hay muchas limitaciones para ascender en la carrera docente. Ascender en cargos en la universidad, a un cierto nivel hay como un tapón que no dejan a los de arriba crecer. Es ahí donde se pierde el criterio de democracia. Hay un tapón para que determinada gente no crezca y otro problema son los interinos que no tienen representación. No sólo quien no está en las listas no se ve nunca beneficiado, sino directamente te ves perjudicado. Te bloquean la posibilidad de trabajo, no podés ascender y no sólo eso, no trabajás cómodo, tenés limitaciones físicas mayores (Entrevista 6).

Uno de los investigadores sostuvo que al mantenerse neutral a las listas de profesores que participan de las elecciones de su claustro en la FFyB, por consecuencia fue penalizado por quienes alternativamente gobiernan su facultad con peores condiciones de trabajo para su cátedra. Señaló que tiene sólo tres dedicaciones exclusivas y tres semi-exclusivas en su cátedra, en la cual dan clase 20 docentes, siete de los cuales lo hacen con dedicaciones ad-honorem. Es decir que en su cátedra hay un 35\% de docentes ad-honorem, porcentaje mayor al promedio de la FFyB. Podemos pensar que este tipo de situaciones afectan también a la autonomía de la razón. Contar con menos dedicaciones exclusivas limita el tiempo que tiene una cátedra para realizar sus proyectos de investigación, obligando a quienes sí mantienen dedicaciones exclusivas a adaptar sus proyectos a un equipo más reducido del que consideran necesario.

Hay componentes políticos dentro de la Facultad que influyen. En general, se generan listas. A mí me dicen que soy huérfano, porque no estoy asociado con ninguno en particular, pero los que participan políticamente, ellos sí siempre tienen recursos, les salen los subsidios y demás (Entrevista 5).

\section{Autonomía de la razón en la FFyB y la influencia del Estado}

Distintos autores han dado cuenta de las amenazas a la autonomía de la razón que se generan ante la venta a privados de las investigaciones. A la hora de conseguir financiamiento que no provenga directamente del PP, se sesgan las investigaciones a aquéllas que sean vendibles restringiendo los márgenes de AU (Slaughter y Leslie, 1999; Arroyo, 2005; Naidorf, 2005; Juarros y Naidorf, 2006; Rikap, 2015b). Sin embargo, Riquelme y Langer (2013) advierten que los investigadores que entrevistaron, entre los cuales un significativo grupo pertenece a la UBA, tienden a no reconocer que la satisfacción de demandas externas desvía sus líneas de investigación y aumenta el peligro de la rutinización de sus actividades. Si bien este riesgo lo hemos identificado también nosotros en nuestras entrevistas a docentes-investigadores de la FFyB de la UBA, al mismo tiempo los investigadores reconocen que hasta los departamentos de investigación básica han buscado orientar al menos una porción de sus investigaciones en línea con demandas privadas.

\footnotetext{
No descartás absolutamente nada de los convenios o asesorías que vienen a causa de la insuficiencia presupuestaria. La descartás si te llega una oferta mejor, pero si no la agarrás igual (Entrevista 6).
}

Entonces, ¿en qué medida se ve afectada la autonomía de la razón en la FFyB? A la hora de responder esta pregunta debemos considerar que la 
vinculación efectiva que realiza esta unidad académica con empresas de capital no está plenamente desarrollada, comparándola por ejemplo con universidades de Estados Unidos (Rikap, 2015a). Si bien todos los investigadores entrevistados reconocieron que la vinculación con el sector privado ha crecido en los últimos 15 años en esta facultad, coinciden en que es aún marginal a juzgar por la relevancia de los principales circuitos de innovación que se crean constantemente en los países centrales.

En biotecnología hay más campos, cosas nuevas que salen y se van aplicando en esta área. Estamos lejos de la biotecnología que se hace en otros lugares, aunque hay buena base. La diferencia con los países centrales, sin dudas, es el financiamiento que te permite avanzar más rápido y, por otro lado, lo que ve gente que hizo cosas afuera es que en nuestra área, por ejemplo en EUA y Canadá, se abren empresas permanentemente alrededor de la universidad; todo tiene líneas donde se aplican. Hay un movimiento que acá no existe. Pero igual el campo se va ampliando. (Entrevista 2).

Podemos pensar entonces que quedan márgenes de tiempo disponibles para actividades no condicionadas. ¿Cómo se determina ese margen? ¿Cómo dividen su jornada de trabajo los investigadores entre tareas en el marco de acuerdos con empresas de capital y su investigación libre? De acuerdo con la reglamentación general de la UBA para vinculación, los investigadores con dedicación exclusiva no pueden dedicar más de un 30\% de su tiempo a convenios con terceros (Resolución Consejo Superior UBA 1655/87). Sin embargo, los investigadores entrevistados en la FFyB (todos ellos con dedicación exclusiva a la investigación) no tienen una noción clara de cómo reparten su jornada de trabajo; en ocasiones los convenios son al mismo tiempo fuente de investigaciones propias de manera que no es sencillo asegurar que esto se cumpla.
Aun si se cumpliera que sólo un $30 \%$ de la jornada se dedicara a actividades de vinculación, la autonomía de la razón peligraría igualmente, dado que perviviría la influencia de las empresas de capital contratantes que buscan orientar las investigaciones en función de la obtención de resultados útiles a sus procesos productivos. Así, si bien pueden ser los propios investigadores quienes elijan producir para el Mercado, su autonomía de la razón se ve comprometida si en lugar de dar rienda suelta a sus ideas, deben circunscribirlas a pensar proyectos comercializables atractivos para las empresas de capital, en un contexto donde todos los entrevistados acuerdan en la insuficiencia del PP para investigación asignado sin condicionamientos. Si eligen no seguir este camino, los recursos no serán suficientes para realizar sus investigaciones, lo cual en definitiva también afecta su autonomía de la razón. Este doble riesgo fue reconocido por la mitad de los investigadores entrevistados.

La búsqueda de autonomía financiera no puede ser reemplazada por una actividad de taller y de servicio [...]. Que venda recursos complementarios a sostener las columnas de la universidad con sus productos de transferencia sí, pero una cuota aparte y ahí soy estatista. El Estado debería sostener el resto. [...] Apuesto a Recursos Propios menores para no exacerbar la universidad taller pero sí usina, incubadora (Entrevista 1).

Otra fuente de limitaciones al tiempo dedicado a investigar, en este caso identificada por todos los docentes-investigadores entrevistados, es el incremento de tareas administrativas, de gestión y para la obtención de recursos tanto públicos como privados. Coinciden en que preferirían poder dedicar esas horas a continuar sus investigaciones.

Ahora bien, la existencia de riesgos en la orientación de las investigaciones no sólo se observa a la hora de firmar un convenio o establecer otro tipo de 
vínculo con empresas de capital. La autonomía de la razón también se ve afectada ante cambios en la relación con el Estado. Probablemente haya sido la creación de la CONEAU la política más rechazada como vulneración de la AU en su dimensión de autonomía de la razón desde la UBA.

Ahora bien, en la FFyB hay un área exclusivamente dedicada a la acreditación de sus carreras a la CONEAU, las cuales fueron tempranamente reconocidas como de interés público y, por lo tanto, se les exigió su acreditación. En 2007, se acreditaron por primera vez las licenciaturas en Farmacia y Bioquímica por seis años. Luego, en 2009, se hizo lo propio con cinco carreras de especialización en Bioquímica Clínica. Entre 2010 y 2011 se reacreditaron las maestrías compartidas con otras unidades académicas de la UBA; en 2012, tres carreras de especialización en Farmacia y se gestionó la reacredicación del doctorado de esta facultad. A diferencia de lo sucedido en la Facultad de Ciencias Exactas y Naturales, este proceso no encontró en la FFyB gran resistencia u oposición, la cual estuvo sólo encarada por grupos minoritarios, principalmente estudiantiles. En congruencia con el escenario general en esta facultad, sólo una porción minoritaria de los entrevistados presenta reparos a las exigencias asociadas con la acreditación.

Una situación particular es la acreditación de las carreras a la CONEAU; el ansia de buscarla hace que se hagan cosas que no corresponden. [...] Lamentablemente, a veces por la acreditación se hacen cosas que sacan y ponen materias; modifican los planes de estudio y a veces se pierde lo esencial por querer acreditar. Y como tengo que tener determinado nivel de aprobados versus desaprobados, porque la acreditación lo exige [...] y yo digo, pará un momento necesito un buen profesional. Yo no voy a darme el lujo de meterme en esas porquerías porque sé que si sale un profesional mal formado puede matar a alguien. Un error en el área de salud es la muerte de alguien (Entrevista 5).
Pero la CONEAU no es la única fuente o mecanismo estatal de influencias sobre la libertad académica. Doberti (2014) señaló que, en general en la UBA, los investigadores participan en los programas públicos cuyas pautas fueron estipuladas externamente influyendo así sobre lo que se investiga. A partir de las respuestas de los entrevistados sugerimos que la adaptación o no a estas líneas, lo cual no siempre depende de la voluntad del científico, sino también del equipamiento disponible en su laboratorio, conforma dos grupos de investigadores. Por un lado, se encuentran aquéllos que se adaptan a los lineamientos estratégicos, orientando en mayor o menor grado sus investigaciones. Si bien estos investigadores no cambian radicalmente su trabajo dentro de su disciplina ni, en general, cambian radicalmente de disciplina, sí orientan la investigación dentro de su área a aquellos temas con más oportunidades de conseguir financiamiento. Ello en un contexto donde, incluso accediendo a esos recursos, los entrevistados coinciden en que perviven limitantes en materia de financiamiento.

Sí, orientamos las investigaciones a las áreas prioritarias, cuando vimos el impacto en salud nos dimos cuenta que la sociedad [...] iba de alguna manera a usufructuar [...] como la sociedad nos paga tenemos que hacer algo por ellos (Entrevista 1).

No es que cambiamos los temas para entrar al sistema, pero sí nos pasó de presentar algo para alguien dentro de lo que considerábamos y luego la evaluación es acotadísima y no entró. Luego dijimos vamos al tema más de lleno estratégico y entró. Esos temas nos dan una visión de por dónde pasa la cosa, pero no nos reducimos a eso porque es un arma de doble filo. Pero no podés hacer caso omiso de que existen, hay que verlos. [...] Lo tenemos en cuenta pero no nos adaptamos 100\% (Entrevista 2).

También encontramos a aquéllos que deciden no seguir las recomendaciones oficiales aun cuando ello signifique trabajar casi sin recursos; o los coloque en 
una situación de mayor vulnerabilidad a la hora de negociar vínculos con empresas de capital. Quienes se encuentran en este grupo saben que deben afrontar las consecuencias de contar con insuficiente financiamiento.

Tuvimos una etapa terriblemente limitada; realmente éramos pobres. Para hacer las extracciones necesitábamos hasta solventes y no me olvido más un día le digo a un compañero si no tenía un poco de metanol porque no teníamos presupuesto ni para eso. Presentamos un proyecto de estudios de plantas medicinales y la respuesta fue no es de interés nacional y entonces se dejó. Nosotros tratábamos de seguir sin recursos y un día nos golpean la puerta compañeros con metanol y así otros. Te das cuenta la solidaridad al interior de la facultad. No es que se me condicionó explícitamente, quizás el condicionamiento puede venir de que a uno le otorgan el subsidio y al otro no, es más sutil la dominación. Es un condicionamiento pero no me cortan la luz, no me echan, etcétera. Actualmente sí estamos mejor, a medida que íbamos avanzando y el tema tomó importancia, conseguimos asesorías (Entrevista 5).

En este escenario, si bien el grado de orientación externa percibido por los investigadores entrevistados fue variable, en general encontramos cierta percepción de que se están produciendo cambios en el quehacer científico al cual los investigadores de la FFyB, más allá del reconocimiento o no de sus riesgos, se estarían adaptando. Estos resultados se ubican entonces en línea con el cambio en la cultura académica identificado por Brotto (1999) y Naidorf (2005).

\section{Reflexiones finales}

La noción de AU atraviesa la historia de la UBA, y es un concepto estructurador de su presente. En cuanto al periodo que nos compete en este trabajo, hemos observado que las necesidades financieras se mantienen como problema significativo en la UBA, reconocido por los docentes-investigadores de la FFyB entrevistados. Sin embargo, encontramos que no es ésta la única explicación de su vinculación con empresas, a juzgar por las motivaciones de dichos entrevistados.

Adicionalmente, expusimos límites asociados a la autonomía corporativa interna de la UBA. Gran parte de los universitarios carece de ciudadanía política, al tiempo que los cientos de miles de estudiantes están sub-representados y los profesores regulares tienen mayoría absoluta. De modo que, a la hora de analizar la vigencia de la autonomía corporativa en la UBA, observamos que quienes detentan la autonomía en la toma de decisiones son un grupo reducido, minoritario con relación al total de universitarios. Podemos pensar que conforman una corporación (o quizás varias dado el peso federativo de la las facultades en la UBA) dentro de la corporación universitaria. $\mathrm{Al}$ respecto, la percepción de los investigadores entrevistados está dividida entre quienes desconocen las estructuras de toma de decisiones y quienes, conociéndolas, reconocen sus limitaciones.

En la FFyB, esta limitación sobre la autonomía corporativa también apareció influyendo sobre las investigaciones. Considerando lo señalado por uno de los entrevistados, se prioriza la asignación de recursos y rentas docentes y de investigación a aquellos grupos afines a quienes gobiernan la facultad. De esta manera, encontramos que la autonomía de la razón también se ve afectada por las limitaciones a la autonomía corporativa en esta facultad.

La autonomía de la razón también peligra a partir de los noventa ante la vinculación privada. Desde ya no estamos afirmando que, con anterioridad, la UBA se rigiera enteramente por el principio de libertad para conocer, pues la idea de ciencia neutral ha sido ya ampliamente criticada evidenciando el sinsentido de pensar que es posible hacer ciencia totalmente al margen de la sociedad. Pero no es igual la influencia recibida por ser parte de su sociedad y por haberse formado en ella, que el limitante que se 
genera cuando es un interés particular el que guía las investigaciones. Un aspecto a seguir explorando es la medida en la cual las orientaciones propuestas para los llamados a financiamientos asignados por mecanismos competitivos de organismos públicos responden a problemáticas sociales generales o a intereses particulares de grupos o sectores vinculados al poder de turno. Este tipo de financiamientos a nivel mundial constituye uno de los mecanismos de control utilizados por el Estado Evaluador.

A partir de las respuestas que hemos obtenido, reforzamos la idea de que se ha transformado la manera de pensar a la propia producción de conocimiento en la UBA, en línea con las conclusiones de Brotto (1999) y Naidorf (2005) sobre un cambio en la cultura académica que admite el direccionamiento privado de al menos una parte de las investigaciones. Los investigadores tratan de conciliar las nuevas reglas de la investigación con la defensa de la autonomía de la razón.

La libertad de investigación es fundamental pero de alguna manera tiene que estar enfocada desde algún punto de vista y el financiamiento tiene que acompañar las ideas que uno tiene. Sí me parece que la libertad para investigar es lo más importante dentro de la autonomía (Entrevista 2).

Es muy importante, muy muy importante [la autonomía universitaria...]. La reforma universitaria puede ser que después de tantos años tenga algunas cosas que puedan ser un obstáculo, pero en realidad uno de los principios, que es la autonomía universitaria, tiene que estar en un país donde el valor de la autonomía sea reconocido. No siempre es así [...] con la libertad académica (Entrevista 3).

Nuestros resultados se ubican en línea con los de Riquelme y Langer (2013); existen grietas o márgenes para investigar con autonomía, aunque los mismos enfrenten restricciones presupuestarias, convivan con investigaciones adaptadas a las necesidades privadas y deban sortear procesos de evaluación interna, atravesados por los intereses corporativos particulares que gobiernan la UBA, y externa para obtener recursos públicos por medio de mecanismos competitivos.

No descartamos que sea posible encontrar, dentro de las líneas de investigación financiadas, espacio para la producción de conocimiento libre. Pero ello exige una gran habilidad y creatividad del investigador universitario, al mismo tiempo que los proyectos que pueda realizar en ese marco difícilmente puedan separarse tajantemente de la orientación del proyecto originalmente financiado. A modo de ejemplo, resumimos una experiencia relatada en la entrevista 3 en el marco de un convenio de asesoría de alta complejidad con Schering. Los investigadores de la FFyB se propusieron ir un paso más y aprovechar los análisis clínicos que estaban realizando para llevar adelante un proyecto novedoso que sí los apasionaba.

\footnotetext{
Dije, "de lo que estamos haciendo por convenio, ¿qué es lo que podemos aprovechar para hacer un trabajo de investigación que nos interese a nosotros?” Nos interesaba por qué en mujeres que pasan la menopausia aparecen infartos y enfermedades cardiovasculares cuando bajan los estrógenos. [...] No nos interesaba tanto el problema farmacológico [para el cual Schering las había contratado], sino el mecanismo de generación de los alteromas (Entrevista 3).
}

Reconocida la existencia de grietas, igualmente consideramos que si se restringe la autonomía de la razón a una porción limitada de tiempo del científico, se corre el riesgo de que los propios investigadores pierdan su capacidad de pensar problemas relevantes, la habilidad de desarrollar sus intuiciones, de elaborar ideas propias. Si ese ejercicio no es fomentado, dado que las investigaciones a realizar ya vienen prefijadas o condicionadas externamente, y se dedica parte del tiempo a satisfacer demandas 
privadas, nada garantiza que el espíritu crítico e inquieto se mantenga.

Finalmente, y considerando las respuestas esgrimidas por los investigadores de la FFyB, es posible pensar que cuando los investigadores se forman creyéndose libres, ellos formalmente eligen presentar tal o cual proyecto para conseguir financiamiento y ellos deciden ofrecer sus capacidades al sector privado bajo la forma de diversos vínculos, esta libertad no coincide

\section{Referencias}

Altbach, Philip (2006), International higher education: reflections on policy and practice, Boston, Boston College Center for International Higher Education.

Anderson, Robert (2004), European universities from the enlightenment to 1914, Oxford, Oxford University Press.

Arroyo, Mariela (2005), "Concepciones del espacio público y sentido común de la educación superior", en Espacio público y privatización del conocimiento. Estudios sobre políticas universitarias en América Latina, Buenos Aires, CLACSO, pp. 27-99.

Beigel, Fernanda (2010), Autonomía y dependencia académica, Buenos Aires, Biblos.

Berman, Elizabeth Popp (2012), Creating the Market University, Princeton, Princeton University Press.

Bermejo Castrillo, Miguel Ángel (2008), "La universidad europea entre ilustración y liberalismo. Eclosión y difusión del modelo alemán y evolución de otros sistemas nacionales", en Filosofia para la universidad, filosofia contra la universidad (de Kant a Nietzsche), Madrid, Dikinson, pp. 49-166.

Blanchet, Alain y Hélène Bézille (1985), L'entretien dans les sciences sociales: l'écoute, la parole et le sens, París, Dunod.

Boveris, Alberto (2009), "El Rol de la UBA en el desarrollo ya con la autonomía de la razón kantiana. En su lugar, se asemeja a la autonomía privada, individual del productor de mercancías que decide qué producir y cómo producirlo (Marx, [1867] 1973). Implícitamente y aunque no lo reconozca, como todo productor de mercancías, está obligado a producir un valor de uso mercantil para garantizar su propia reproducción. El cambio en la cultura académica acerca entonces al investigador a la figura del productor de mercancías.

científico argentino", en Encrucïadas, 47, <http://www. uba.ar/encrucijadas/47/sumario/enc47-desarrollocientificoarg.php> [Consulta: noviembre de 2013]

Brotto, Adriana (1999), "Los 'Recursos Propios' en el Presupuesto Universitario", en La educación superior en la Argentina. Transformaciones, debates, desafios, Buenos Aires, Ministerio de Cultura y Educación de la Argentina, pp. 293-294.

Brunner, José Joaquín (2012), "La idea de universidad en tiempos de masificación", en Revista Iberoamericana de Educación Superior (RIES), III (7), pp. 130-143.

Buchbinder, Pablo (2006), "Viñas de ira en la UBA", en Le Monde Diplomatique, Edición Cono Sur, Buenos Aires, núm. 85, pp. 12-13, <http://www.insumisos.com/ diplo/NODE/881.HTM> [Consulta: diciembre de $2014]$.

Buchbinder, Pablo (2005), Historia de las universidades argentinas, Buenos Aires, Editorial Sudamericana.

Buchbinder, Pablo (2004), "Lucha facciosa y debilidad institucional", en Le Monde Diplomatique, Edición Cono Sur, Buenos Aires, núm. 63, pp. 34-35, <http:// www.insumisos.com/diplo/NODE/1881.HTM> [Consulta: junio de 2014]. 
Buchbinder, Pablo y Mónica Marquina (2008), Masividad, heterogeneidad y fragmentación. El sistema universitario argentino 1983-2008, Buenos Aires, Biblioteca Nacional y Universidad Nacional General Sarmiento.

Castro Martínez, Elena y Judith Sutz (2011), "Universidad, conocimiento e innovación", en Ciencia, tecnologíay universidad en Iberoamérica, Buenos Aires, Eudeba, pp. 101-117.

Cummings, William, Donald Fisher y William Locke (2011), "Introduction", en Changing governance and management in higher education: The perspectives of the academy, vol. 2, Londres y Nueva York, Springer Science \& Business Media, pp. 1-16.

DiMeglio, María Fernanda y Elizabeth López Bidone (2010), "Contribuciones al proceso innovativo regional a partir de la vinculación universidad-empresa. Caso de estudio: polo informático UNICEN", en Transformaciones recientes de las universidades latinoamericanas. Agendas y actores en la producción de conocimiento, Argentina-México, BUAP/UNCPBAUAZ, pp. 217-246.

Doberti, Juan (2014), "La organización académica en la Universidad: el caso de la UBA", Tesis de Doctorado, Buenos Aires, Facultad de Ciencias Económicas de la UBA. Facultad de Farmacia y Bioquímica (FFyB) (2015), Memoria 2012/2013, Buenos Aires, UBA-FFyB.

FFyB (2014), Plan Estratégico 2014-2018, Buenos Aires, UBA-FFyB.

FFyB (2013), Memoria 2010/2011, Buenos Aires, UBA-FFyB. FFyB (2011), Memoria 2008/2009, Buenos Aires, UBA-FFyB. FFyB (2009), Memoria 2006/2007, Buenos Aires, UBA-FFyB. Fernández Lamarra, Norberto, Mónica Marquina y Gabriel Rebello (2011), "Argentina: changes in academics' involvement in the governance and management of public universities", en Changing governance and management in higher education, Holanda, Springer Netherlands, pp. 19-33.

Finocchiaro, Alejandro (2004), UBA c/Estado Nacional. Un estudio sobre la autonomía universitaria, Buenos Aires, Prometeo 3010.

Furman, Jeffrey y Megan Mac Garvie (2009), "Academic collaboration and organizational innovation: The development of research capabilities in the US pharmaceutical industry, 1927-1946”, en Industrial and Corporate Change, 18(5), pp. 929-961.

García de Fanelli, Ana María (2007), "The challenge of building research universities in middle-income countries: the case of the University of Buenos Aires", en World Class Worldwide Transforming Research Universities in Asia and Latin America, Baltimore, Johns Hopkins University Press, pp. 260-285.

García de Fanelli, Ana María (1993), La articulación de la Universidad de Buenos Aires con el sector productivo: la experiencia reciente, Buenos Aires, Documentos CEDES 96.

Gentili, Pablo y Bettina Levy (2005), Espacio público y privatización del conocimiento. Estudios sobre politicas universitarias en América Latina, Buenos Aires, CLACSO.

Gieysztor, Alexander ([1992]2003), "Administración y recursos", en Las universidades en la Edad Media: historia de la universidad en Europa, vol. 1, Bilbao, Universidad del País Vasco, pp. 121-162.

Harari-Kermadec, Hugo (2016), "Fraisd'inscription et quantification néolibérale de l'Université", Presentación para habilitación a defender tesis de doctorado, París.

Hazelkorn, Ellen (2005), University research management. Developing research in new institutions, París, OECD Publishing.

Johnstone, D. Bruce (2012), "Worldwide trends in financing higher education: a conceptual framework", en Educación superior y sociedad, núm. 6, pp. 105-122.

Juarros, Fernanda (2006), "La vinculación universidadempresa-sector de la producción de bienes y servicios, vista por los docentes investigadores. El caso de la Facultad de Farmacia y Bioquímica de la Universidad de Buenos Aires", en La vinculación universidad-empresa: miradas críticas desde la universidad pública, Buenos Aires, Miño y Dávila, pp. 171-212.

Juarros, Fernanda y Judith Naidorf (2006), "Políticas científicas y tecnológicas para la promoción en Argentina de la vinculación universidad-empresa", en La vinculación universidad-empresa: miradas críticas desde la universidad pública, Buenos Aires, Miño y Dávila, pp. 71-89. 
Kandel, Victoria (2005), "Formas de gobierno en la universidad pública: reflexiones sobre la colegiación y la democracia", en Espacio público y privatización del conocimiento. Estudios sobre políticas universitarias en América Latina, Buenos Aires, CLACSO, pp. 259-294.

Kant, Immanuel ([1784]2009), Contestación a la pregunta: ¿Qué es la Ilustración?, Madrid, Alianza.

Kleinman, Daniel y Steven Vallas (2001), "Science, capitalism, and the rise of the 'knowledge worker': The changing structure of knowledge production in the United States", en Theory and Society, vol. 4, núm. 30, pp. 451-492.

Krotsch, Pedro (1990), "Organización, gobierno y evaluación universitaria", en Universidad y evaluación (101-136). Estado del debate, Buenos Aires, Ideas.

Levín, Pablo (1997), El Capital Tecnológico, Buenos Aires, Catálogos.

Libecap, Gary (2005), "Introduction", en University entrepreneurship and technology transfer: process, design, and intellectual property, Reino Unido, Elsevier, pp. ix-xviii.

Llomovatte, Silvia (2006), La vinculación universidad-empresa: miradas críticas desde la universidad pública, Buenos Aires, Miño y Dávila.

Marx, Karl ([1867]1973), El Capital. Crítica de la Economía Política (Tomo I), México, Fondo de Cultura Económica.

Michael, Steve (2005), "Financing higher education in a global market: A contextual background", en Financing Higher Education in a Global Market, Nueva York, Algora Publishing, pp. 3-32.

Ministerio de Educación (2011), Anuarios de Estadísticas Universitarias, Buenos Aires, <http://portales.educacion. gov.ar/spu/investigacion-yestadisticas/anuarios/> [Consulta: julio de 2015].

Morgan, Keith (2011), "Where is von Humboldt's University now?", en Research in Higher Education-Daigaku Ronshu, núm. 42, pp. 325-344.

Naidorf, Judith (2005), "La privatización del conocimiento público en universidades públicas", en Espacio público y privatización del conocimiento, Buenos Aires, CLACSO, pp. 101-162.

Neave, Guy (2012), The evaluative state, institutional autonomy and reengineering higher education in Western Europe, Reino Unido, Palgrave Macmillan.

Neave, Guy (1988), "On the cultivation of quality, efficiency and enterprise: an overview of recent trends in higher education in Western Europe 1986-1988”, en European Fournal of Education, núm. 23, pp. 7-23.

Piironen, Ossi (2013), "The transnational idea of university autonomy and the reform of the Finnish Universities Act”, en Higher Education Policy, núm. 26, pp. 127-146.

Rikap, Cecilia (2015a), "Contribución a la economía política de la Universidad. La Facultad de Farmacia y Bioquímica de la Universidad de Buenos Aires como observatorio privilegiado", Tesis de Doctorado, Buenos Aires, Facultad de Ciencias Económicas de la UBA.

Rikap, Cecilia (2015b), "Autonomía Universitaria en la Universidad de Buenos Aires", en XI fornadas de Sociología de la UBA, Buenos Aires, Facultad de Ciencias Sociales, UBA.

Rikap, Cecilia (2014), "La Universidad en el contexto del capital no diferenciado: ámbito autónomo de relación poiética", en Apuntes para el Metaplán, Buenos Aires, Facultad de Ciencias Económicas, UBA, pp. 17-52.

Rikap, Cecilia (2012), "La vinculación de la Universidad con el sector productivo: transferencia tecnológica", en Ecos de Economía, 34(16), pp.127-149.

Riquelme, Graciela y Ariel Langer (2013), "Los docentes universitarios y la producción y circulación del conocimiento: un estudio sobre universidades argentinas", en CIAN-Revista de Historia de las Universidades, 16(1), pp. 1-114.

Rüegg, Walter (2003), Historia de la Universidad en Europa. Volumen I. Las Universidades en la Edad Media, Bilbao, Universidad del País Vasco.

Saltalamacchia, Homero (1997), El proyecto de investigación, su estructura y redacción, Puerto Rico, Cuadernos del CAPEDCOM.

Slaughter, Sheila y Larry Leslie (1999), Academic capitalism: politics, policies, and the Entrepreneurial University, Baltimore, Johns Hopkins University Press.

Toscano, Ariel (2005), "Análisis exploratorio de los 
efectos del FOMEC y la CONEAU en las universidades argentinas: ¿erosión de la frontera entre lo público y lo privado?”, en Espacio público y privatización del conocimiento. Estudios sobre políticas universitarias en América Latina, Buenos Aires, CLACSO, pp. 343-400. Universidad de Buenos Aires (UBA) (2011a), Genso de Docentes, Buenos Aires, <http://www.uba.ar/ institucional/contenidos.php?id=194> [Consulta: mayo de 2014].

UBA (2011b), Censo de Estudiantes, Buenos Aires, <http://www.uba.ar/institucional/contenidos. php?id=194> [Consulta: noviembre de 2015].

UBA (1960), Estatuto Universitario, Buenos Aires, <http://www.uba.ar/download/institucional/uba/932.pdf $>$ [Consulta: febrero de 2014].

Varsavsky, Oscar (1969), Ciencia, política y cientificismo, Buenos Aires, Ediciones de la Feria/ Centro Editor de América Latina.

Vincent-Lancrin, Stéphan (2006), "What is changing in academic research? Trends and futures scenarios", en European fournal of Education, vol. 2, núm. 41, pp. 169202.

\section{Anexo 1. Guía de pautas de las entrevistas a investigadores de la FFyB}

\section{A. Datos fácticos}

Información Personal.

Profesión /antigüedad en la profesión

1. ¿Hace cuántos años que da clases en la FFyB?

2. ¿Hace cuántos años que percibe renta por sus cargos en la FFyB?

3. ¿Hace cuántos años que investiga en la FFyB?

4. ¿Es investigador del CONICET?

5 y 6. ¿Realiza otra actividad laboral además de la docencia y la investigación? Si contesta que sí, ¿qué?

7. ¿Por qué ha decidido dedicarse a la docencia y la investigación universitarias?

8. ¿Cuán relacionados se encuentran los temas que enseña en el grado con los contenidos de sus investigaciones?

9, 10 y 11. A lo largo de su carrera como docente-investigador/a ¿ha visto modificada la especialización de sus investigaciones? Si contesta que sí: ¿Cuándo? ¿A qué lo atribuye?

12. En cuanto a la especialización de sus investigaciones. En los últimos 15 años:

a) Se han profundizado las investigaciones asociadas a problemas particulares o especializados

b) Se ha mantenido estable el grado de especialización de mis investigaciones

c) Ha disminuido el grado de especialización de mis investigaciones

d) No sabe, no contesta

13. En cuanto a la disponibilidad de recursos para realizar sus investigaciones. En los últimos 15 años, ¿ha debido modificar al menos parcialmente la temática de sus investigaciones por no contar con los fondos suficientes?

Datos sobre el instituto de pertenencia.

14. ¿Con qué tipo de financiamiento cuenta actualmente? (marcar todas las correctas y si son varias preguntar el peso de cada una sobre el total de recursos percibidos)
a) UBCYT
b) PICT
c) Otros del sector público
d) Organismos internacionales
e) Fondos privados
f) Otros: ¿cuáles? 
15 y 16. Si contesta que recibe fondos privados: ¿Qué tipo de fondos y quién es la contraparte? ¿Qué tipo de vínculo ha establecido con la contraparte (asistencia técnica, alta complejidad, transferencia tecnológica, otra)? ¿Cómo ha sido este vínculo y quién lo gestiona?

17. ¿Con qué frecuencia obtienen financiamiento privado en su instituto?

18. Los proyectos con terceros se llevan a cabo:

a) A nivel individual (cada investigador tiene los suyos)

b) En subgrupos o centros dentro del instituto

c) A nivel global del instituto

d) Otra:

19. En cuanto a la contraparte, en general se trata de:

a) Alguna dependencia pública

b) Empresas pequeñas o medianas

c) Grandes empresas pioneras en innovación

d) Organismos sin fines de lucro

e) Otra universidad

f) Otra:

\section{B. Percepción de cambios}

Sobre la concepción del conocimiento producido en la universidad.

20. ¿Considera que, a nivel general, las investigaciones en su disciplina han avanzado hacia una mayor especialización en una problemática particular o hacia problemáticas más generales o abarcativas?

21. ¿Cómo evaluaría el proceso de vinculación con el sector privado?

a) Ha crecido a lo largo de los últimos 15 años

b) Se ha mantenido estable a lo largo de los últimos 15 años

c) Ha disminuido a lo largo de los últimos 15 años

d) No realizo transferencia.

e) No sabe, no contesta

22. Si elige d, preguntar: ¿por qué?

23. Si elige a, b o c preguntar: a qué atribuye esta situación?

24. y 25. La vinculación con el sector privado, ¿ha influido en la agenda de investigación de su instituto o de sus investigadores? Si contesta que sí: ¿en qué aspectos?

26 y 27. ¿Considera adecuada/útil la clasificación de los convenios según: asistencia técnica, alta complejidad y transferenciatecnológica? ¿ por qué?

28. Como parte de mi tesis me he propuesto desarrollar una nueva clasificación que dé cuenta de las particularidades de los convenios no en términos legales sino en función de si corresponden a actividades eminentemente creativas o si mayoritariamente implican tareas repetitivas. ¿Le parecería útil y factible una clasificación de este tipo? ¿Por qué? (muestro detalle de qué significa cada categoría)

Al momento, la clasificación que he sugerido es la siguiente:

1. Asistencia técnica

2. Dictado de clases o cursos

3. Formación de recursos humanos

4. Intercambio académico o coordinación (IAC) con otras instituciones de educación superior

5. Vinculación técnica de alta complejidad

6. Potencial desarrollo tecnológico

29 y 30. ¿Le resulta útil? ¿Introduciría algún cambio?

Sobre las condiciones de trabajo docentes y como investigadores

31. ¿Cuál cree que son los principales problemas que enfrenta actualmente la docencia universitaria en la FFyB?

32. ¿Cuál cree que son los principales problemas que enfrenta actualmente la investigación en la FFyB? 
33. De los siguientes problemas y en función de su experiencia en la FFyB, ¿cómo los jerarquizaría en orden de mayor importancia o gravedad?

- Docencia ad-honorem

- División entre las tareas de enseñanza e investigación

- Subrogancia

- Docencia interina

- Ausencia de designaciones

Insuficiencia de dedicaciones a la investigación

\section{Sobre la autonomía universitaria.}

34. Si consideramos tres dimensiones de la AU (corporativa, de la razón y financiera), ¿en qué orden de importancia las ubicaría y por qué? (explico qué entiendo por cada una)

35. ¿Qué cambios realizaría, si es que algunos, a los órganos de cogobierno de la FFyB, en particular, y de la UBA, en general?

36. Si no lo menciona preguntar: ¿Considera que un cambio necesario es la conformación de un claustro único docente?

37 y 38. ¿Considera que el vínculo con el sector privado puede afectar la autonomía de la razón/académica? ¿Por qué y cómo?

39. y 40. La existencia de líneas estratégicas fijadas a nivel estatal y asociadas a líneas de financiamiento o becas, ¿considera que ha orientado las investigaciones en su disciplina? ¿Por qué? ¿De qué modo?

41. Finalmente, ¿considera necesario un aumento del Presupuesto Público para las universidades públicas en general y para la UBA, en particular?

42. Si contesta que sí: ¿para qué debería utilizarse prioritariamente ese mayor financiamiento?

\section{Cómo citar este artículo:}

Rikap, Cecilia (2017), "Percepciones sobre la autonomía universitaria de los docentes-investigadores de la Facultad de Farmacia y Bioquímica de la Universidad de Buenos Aires", en Revista Iberoamericana de Educación Superior (RIES), México, UNAM-IISUE/Universia, vol. VIII, núm. 23, pp. 138-162, [consulta: fecha de última consulta]. 